\title{
Emerging role and therapeutic application of exosome in hepatitis virus infection and associated diseases
}

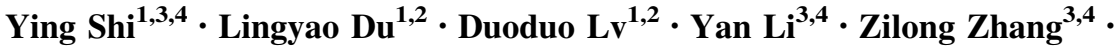 \\ Xiaolun Huang ${ }^{3,4} \cdot$ Hong Tang ${ }^{1,2}$
}

Received: 19 November 2020/ Accepted: 23 January 2021 / Published online: 4 March 2021

(C) The Author(s) 2021

\begin{abstract}
Hepatitis viruses are chief pathogens of hepatitis and end-stage liver diseases. Their replication and related pathogenic process highly rely on the host micro-environment and multiple cellular elements, including exosomes. Representing with a sort of cell-derived vesicle structure, exosomes were considered to be dispensable cellular components, even wastes. Along with advancing investigation, a specific profile of exosome in driving hepatitis viruses' infection and hepatic disease progression is revealed. Exosomes greatly affect the pathogenesis of hepatitis viruses by mediating their replication and modulating the host immune responses. The characteristics of host exosomes are markedly changed after infection with hepatitis viruses. Exosomes released from hepatitis virusinfected cells can carry viral nucleic or protein
\end{abstract}

Ying Shi and Lingyao Du contribute equally to this manuscript.

Hong Tang

htang6198@hotmail.com

1 Center of Infectious Diseases, West China Hospital of Sichuan University, No. 37 Guoxue Alley, Wuhou District, Chengdu 610041, Sichuan, China

2 Division of Infectious Diseases, State Key Laboratory of Biotherapy and Center of Infectious Diseases, West China Hospital, Sichuan University, No. 17 People's South Road, Chengdu 610041, Sichuan, China

3 School of Medicine, University of Electronic Science and Technology of China, No. 4 Section 2, North Jianshe Road, Chengdu 610054, Sichuan, China

4 Department of Hepatobiliary Surgery and Cell Transplantation Center, Sichuan Academy of Medical Sciences and Sichuan Provincial People's Hospital, No. 32 Western Section 2, 1st Ring Rd., Chengdu 610072, Sichuan, China components, thereby acting as an effective subterfuge for hepatitis viruses by participating in viral transportation and immune escape. On the contrary, immune cell-derived exosomes contribute toward the innate antiviral immune defense and virus eradication. There is growing evidence supporting the application of exosomal biomarkers for predicting disease progress or therapeutic outcome, while exosomal nanoshuttles are regarded as promising therapeutic options based on their delivery properties and immune compatibility. In this review, we summarize the biogenesis and secretion mechanism of exosomes, review the recent findings pertaining to the role of exosomes in the interplay between hepatitis viruses and innate immune responses, and conclude their potential in further therapeutic application.

Keywords Exosome - Hepatitis virus - Immune escape · Immune response $\cdot$ Exosomal nanoshuttle

\begin{tabular}{|c|c|}
\hline \multicolumn{2}{|c|}{ Abbreviations } \\
\hline cccDNA & Covalently closed circular DNA \\
\hline $\mathrm{CHB}$ & Chronic hepatitis B \\
\hline DC & Dendritic cell \\
\hline ESCRT & $\begin{array}{l}\text { Endosomal sorting complex required } \\
\text { transport }\end{array}$ \\
\hline $\mathrm{EV}$ & Extracellular vehicles \\
\hline HBV & Hepatitis B virus \\
\hline $\mathrm{HCV}$ & Hepatitis $C$ virus \\
\hline $\mathrm{HCC}$ & Hepatocellular carcinoma \\
\hline IFN & Interferon \\
\hline miRNA & MicroRNA \\
\hline MHC & Major histocompatibility complex, \\
\hline MVB & Multivesicular body \\
\hline NCR & Natural cytotoxicity receptors \\
\hline
\end{tabular}




$\begin{array}{lll}\begin{array}{l}\text { NKT } \\ \text { cell }\end{array} & \text { Natural killer T cell } \\ \text { NK cell } & \text { Natural killer cell } & \\ \text { NKG2D } & \text { Natural killer cell group 2D receptor } & \\ \text { PRR } & \text { Pattern recognition receptor } \\ \text { ESCRT } & \begin{array}{l}\text { Endosomal sorting complex required for } \\ \text { transport }\end{array} & \\ \text { ORF } & \text { Open reading frames } \\ \text { SVR } & \text { Sustained viral response } \\ \text { TLRs } & \text { Toll-like receptors } \\ \text { TNF } & \begin{array}{l}\text { Tumor necrosis factor } \\ \text { TRIF }\end{array} & \begin{array}{l}\text { Toll/IL-1 receptor domain-containing adaptor- } \\ \text { inducing IFN- } \beta\end{array} \\ \text { TSG101 } & \text { Tumor susceptibility gene 101 } & \\ \text { VAPA } & \text { Vesicle-associated membrane } & \text { protein- } \\ & \text { associated protein A } & \\ \text { VPS } & \text { Vacuolar protein sorting-associated protein } \\ & \text { family }\end{array}$

\section{Introduction}

Hepatitis virus infection remains a severe public health problem with considerable morbidity and mortality, leading to about 1.5 million deaths on a global scale annually [1]. Commonly, hepatitis viruses consist of five major groups: hepatitis A virus (HAV), HBV, HCV, HDV and $\mathrm{HEV}$, though other hepatotropic viruses are now under continuously investigating. Prevalence of each kind of hepatitis virus shows distinct geographical localization, while HBV and HCV cause the most serious socioeconomic burdens, especially in developing areas such as those in Africa and Asia [2]. With significant advances in antiviral agents, eradication of HCV is achieved through directly acting antivirals (DAAs). However, therapy of HBV remains an unmet issue due to the limited antiviral efficacy of current anti-HBV options when facing covalently closed circular DNA (cccDNA) [3].

Hepatitis viruses utilize the host materials for replication and establish long-term localization. Their life cycle begins with attaching and entering into hepatocytes, which requires unique receptors located on the cell surface, such as sodium taurocholate cotransporting polypeptide (NTCP) for HBV and CD81 for HCV [4, 5]. Subsequently, hepatitis viruses hijack the host transcriptional machinery and cellular materials for their replication. Uncontrolled viral replication leads to massive hepatocyte necrosis and inflammatory infiltration as well as the development of severe progressive syndromes like cirrhosis, hepatocellular carcinoma (HCC), or other critical illnesses [6].
Over the past decades, extracellular vehicles (EVs) have been shown to play irreplaceable roles in the interplay between hepatitis viruses and the host immune system [7]. Derived from the fusion of multivesicular bodies (MVBs) with the plasma membrane, EVs can carry and transport biologically active molecules to target cells, deliver specific signals to regulate a wide range of processes. Development in the technology of exosome collection and purification supports to find that hepatitis viral genome or proteins can be packaged into exosomes. In pathological conditions, these specific exosomes provide a stretch for viral replication and immune escape. In this review, we summarized recent studies on exosomes related to the hepatitis viruses and reviewed the dual role of exosomes in the mutually dependent relationship between viral pathogenesis and immune response.

\section{The essence of exosome}

EVs represent a broad category of cell-derived particles coated with a lipid bilayer, which can be classified into exosomes, microvesicles, and apoptotic bodies based on their modes of biogenesis. Exosomes are endosomal-origin phospholipid nanovesicles with a typical cup-shape morphology and are 30-150 $\mathrm{nm}$ in diameter, which can be found in almost all eukaryotic fluids, like blood, urine, and cultured medium of cell cultures, and can be isolated using their specific sedimentation properties with a high-velocity centrifuge or an organic solvent-aided sedimentation process $[8,9]$. The composition of exosomes derived from various cell sources varies in quantity and type, while several conserved protein groups have been identified as universal markers based on mass spectrometry-based proteomic and lipidomic analyses. An example is the tetraspanin family of proteins, also known as the transmembrane 4 superfamily (including CD9, CD63, and CD81 among other members) comprising four hydrophobic domains, which are embedded in the membrane of various cells. Their conserved transmembrane structure forms channels to connect the inside of the cells with the outside environment [10]. Heat shock proteins (HSP70, HSP90) are also ranked among the top exosomal markers, which assist membrane remodeling by regulating protein folding and transformation. Other common exosomal components like MVB biogenesis molecules (Alix and TSG101) [11] and GTPases exist in universal structural components of almost all exosomes, and are considered to be common exosomal markers [12]. Specific cell-derived exosomes contain distinct molecules, for example, MHC class I and II are more commonly seen in exosomes released from B lymphocytes, T lymphocytes, and dendritic cells (DCs) [13]. Except for surface protein markers, the lipids or lipoid 
components are essential components involved in membrane trafficking, antigen presentation, target adhesion, and so on. The classical components of the exosomal membrane include cholesterols, ceramides, lipid rafts, and sphingomyelin that form the basic bilayer membrane structure [14]. Besides, the administration of palmitate or its metabolite, lysophosphatidylcholine, has also been suggested to contribute in the release of exosomes [15].

Exosomes originate from membrane cavities or early intracellular bodies, which sag inward to form the endovascular vacuoles and MVBs, following which the MVBs fuse with the cell surface under the traction of intracellular molecular motors to release the exosomes. Some components sorted by the endosome can be presented in this process for exosome packaging. Biogenesis of exosome involves multiple membrane rupture or formation processes and is under the control of the cellular endosomal sorting complex required for transport (ESCRT) pathway through the regulation of the sorting ubiquitinated endocytic cargo (Fig. 1) [16, 17]. ESCRT machinery is composed of four heterodimeric subcomplexes, including ESCRT-0, ESCRT-I, ESCRT-II, and ESCRT-III; each complex has a unique accessory component of vacuolar protein sorting-associated protein (VPS). ESCRT machinery are employed in the inward budding of endosomal membranes; ESCRT-0, ESCRT-I, and ESCRT-II complexes act consequently to sort the ubiquitinated cargo via their ubiquitin-binding domains, and distinct transmembrane proteins are recruited to activate ESCRT-III, which are then incorporated into the invaginated membrane. The cytosolic components are engulfed within the ILVs (intraluminal vesicles), this process is affected by lysobisphosphatidic acid (LBPA) following the correct incorporation of MVBs [18-20]. Part of intracellular MVBs are transmitted to the lysosomes where they are subjected to proteasomal degradation, following which they fuse with lysosomes [21]. Alternatively, a portion of MVBs fuse with the plasma membrane and bud their contents out, which are defined as exosomes [22, 23].

Once released into the external environment, exosomes can be absorbed directly by the adjacent recipient cells, by cells far apart through the paracrine pathway, or they can be circulated before being absorbed through the endocrine pathway. The host-derived element on the surface of the exosome protects it from immune elimination and supports its separation in almost all eukaryotic fluids, such as blood, urine, and also the cultured medium of cell cultures in vitro. When accessing the recipient cells, most exosomes are recognized by cell adhesion factors such as integrin followed by endocytosis, while some can directly fuse with

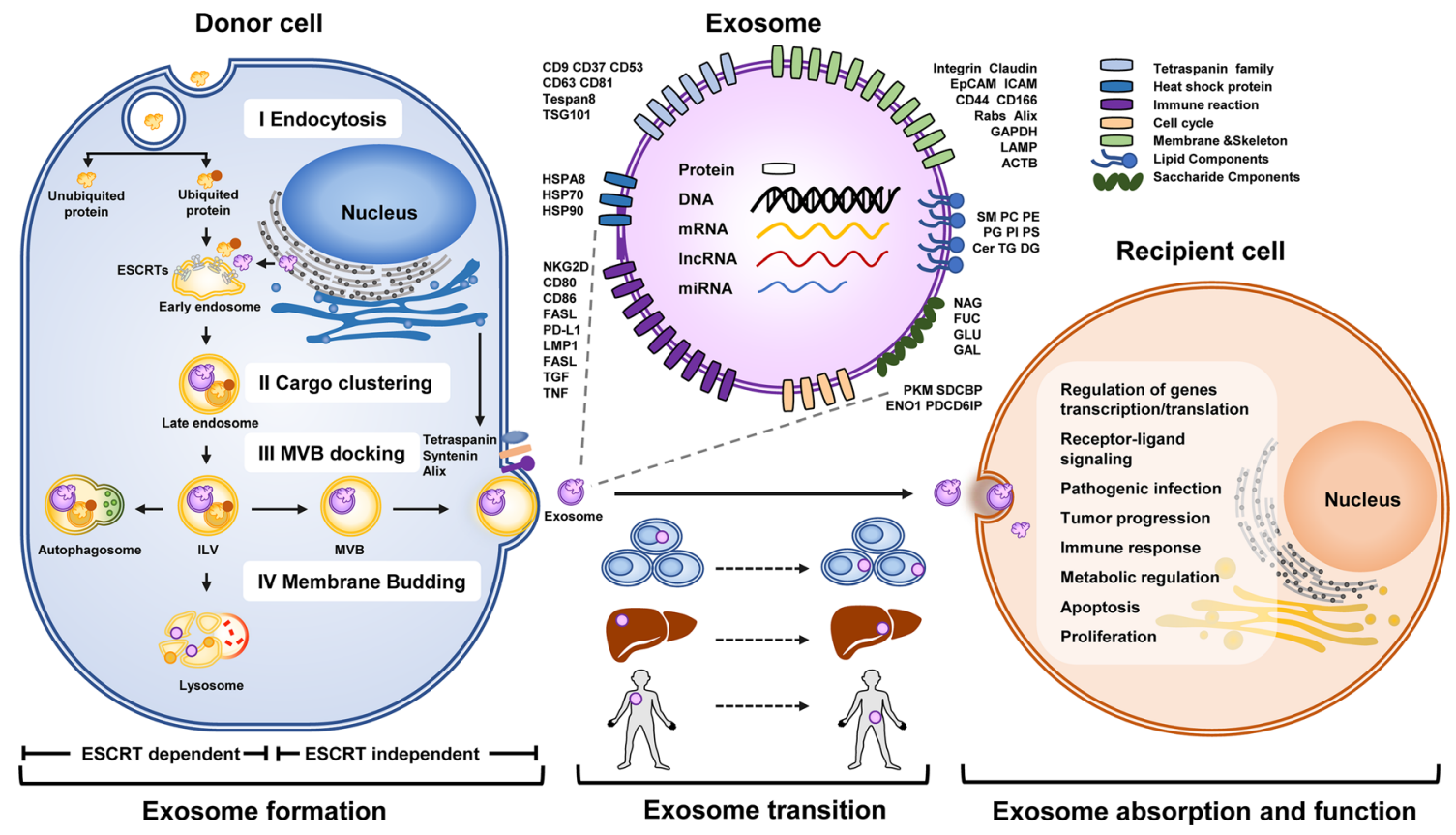

Fig. 1 Biogenesis and function of exosomes. During ESCRTdependent exosome formation: I. proteins are endocytosed from plasma membrane to be incorporated into endocytic vesicles. Ubiquited proteins combine with ubiquitin-binding domain of ESCRTs on early endosome; II. Proteins are sorted via late endosome and intraluminal vesicle; III. A portion of these cargos transport MVBs to dock on the plasma membrane, while the rest are fused with autophagosome and lysosome to degradation; IV. MVBs fuse with the plasma membrane and bud their contents out. Meanwhile, distinct transmembrane proteins are recruited to the plasma membrane where MVBs are docking, helping the final formation and release of exosome in an ESCRT-independent way. Exosome released from donor cells can be absorbed directly by the adjacent recipient cells or undergoes the paracrine pathway and endocrine pathway. After being absorbed into recipient cells, exosome bud contents out to participated in various biological processes 
the recipient cell membrane. In certain cases, the transmembrane protein on the exosome can target factors located on the surface of the recipient cell, thereby initiating the signal transformation process.

Exosomes that were initially regarded as a cellular waste have now been shown to play key roles in various biological processes. Exosomes dispose waste products to maintain cellular homeostasis in donor cells and regulate numerous physiological and pathological processes in recipient cells, thereby exerting a bilateral function. The role of exosome is more complicated in morbid status as they express only selective contents compared to that in the normal condition, especially in tumor status and pathogenic infection. Numerous viruses, such as paramyxoviruses, rhabdoviruses, herpesviruses, filoviruses, and arenaviruses, can exploit the ESCRT machinery to mediate the formation and release of infectious particles directly [24]. Nevertheless, exosomes may act as antigen-presenting vesicles to participate in the immune response, and affect the progression of multiple virus-related diseases. Several studies have demonstrated that exosomal miRNAs derived from hepatitis virus-infected cells can regulate the expression of target genes in the initial stages of liver fibrosis and carcinogenesis [25].

\section{Exosomes in hepatitis virus infection}

\section{Exosomes participate in life cycle of hepatitis viruses}

Accelerating studies have unearthed that exosome can serve as viral carriers, thereby contributing to viral replication or pathogenesis directly. The first evidence comes from the understanding that components of ESCRT are required during viral capsid packaging and the maturation of numerous enveloped viruses [26, 27]. In addition to the classical replication pattern, current research illustrated the viral component to exist in the exosome, thereby demonstrating that hepatitis viruses adopt the exosomes to transmit their genome and establish productive infection (Table 1). For those viruses, it is a viable way to hide within exosomes and escape from immune detection through the ESCRT-dependent viral budding mode [28].

\section{Exosome mediates $H B V$ replication and transition}

HBV infection results in about 257 million chronic hepatitis patients and 887,000 annual deaths worldwide [29]. The virion is a para-retrovirus containing a partial doublestranded and relaxed circular DNA (rcDNA) [30]. Once being engulfed by hepatocytes, rcDNA get fixed and conversed to cccDNA and transcribed into HBV RNAs with different lengths and roles, such as the pregenomic RNA
(pgRNA) and precore mRNA [31]. pgRNA encodes core protein and $\mathrm{P}$ protein to assemble the core particle of $\mathrm{HBV}$, while precore mRNA encodes the secretory protein HBeAg. Subsequently, HBV core particle is completely packaged into an icosahedral capsid to form a replication intermediate sphere with a diameter of $42 \mathrm{~nm}$, then being released out from the original infected cells [32]. Persistence of cccDNA results in long-term chronic infection and treatment failure with nucleos(t)ide analogues (NA) and pegylated-interferon (PEG-IFN) in chronic hepatitis B (CHB) patients.

During the formation of HBV virions, multiple host proteins are expropriated by HBV to catalyze membrane fission, virion package, or release sorting signals. With the high comparability in shape and particle structure, the steps of HBV budding and exit from host cells are associated with ESCRT. Previous studies have confirmed that changes in the microenvironment of HBV infected hepatocytes include factors involved in exosome morphogenesis and protein secretion, such as Annexin A1/A4, COPB1/2, and vesicle-associated membrane protein-associated protein $A$ (VAPA) [33]. Both the whole viral particle and single viral proteins can trigger exosomal protein expression. For example, taxilin alpha (TXLNA) -mediated interaction between HBsAg and the ESCRT component, TSG101, promotes the secretion of viral sub-particles containing liver-specific miRNAs [34, 35]. Likewise, the HBx protein can interact with exosomal biomarkers, such as CD9 and CD81, by utilizing the ESCRT machinery to enhance exosome secretion. Furthermore, the extracellular matrix of HBV infected cells is greatly reshaped compared to normal cells. Quantitative proteomic analysis revealed that HBV or HBx not only changed the exosome contents but also influenced key factors of the extracellular matrix, such as vimentin (VIM) and keratin (KRT)18, inducing re-construction of local hepatic structure and fibrosis directly [36].

Exosome acts as a powerful carrier of viral DNA and protein components, shuttling them from infected to noninfected cells to facilitate HBV spread. HBV virions have been observed to be localized to the membranes of the late endosomes and large intracellular compartments, indicating ESCRT effect in ensheathing HBV somehow [37]. Deficiency of ESCRT impairs HBV budding and/or release. The first evidence comes that when essential genes of ESCRT like actin-interaction protein (AIP) 1 or VPS4B were mutated, production of MVB was attenuated and inhibited extracellular enveloped HBV virions [38]. A more direct evidence is that $\mathrm{HBV}$ components was detected in exosomes purified from the serum of CHB patients, including nucleic acids like cccDNA and rcDNA as well as viral proteins like $\mathrm{HBx}$ and $\mathrm{HBsAg}$ [39]. Abundant HBV DNA has been detected in exosomes isolated from HBV- 
Table 1 Function of hepatitis viruses induced exosome

\begin{tabular}{|c|c|c|c|c|c|}
\hline $\begin{array}{l}\text { Viral } \\
\text { type }\end{array}$ & $\begin{array}{l}\text { Containing } \\
\text { factor }\end{array}$ & Donor cell & Recipient cell & Biological function & References \\
\hline \multirow[t]{6}{*}{ HBV } & RNA & Hepatocyte & NK cells & Promote innate anti-HBV immune response & {$[70]$} \\
\hline & DNA & Hepatocyte & Hepatocyte & Resistant to antibody neutralization & {$[40]$} \\
\hline & DNA & Sera of CHB patients & Hepatocyte & NK-cell dysfunction & {$[39]$} \\
\hline & RNA & Hepatocyte & THP1 cell & Activate innate immunity to restrict $\mathrm{HBV}$ replication & {$[114]$} \\
\hline & $\begin{array}{l}\mathrm{HBx} \\
\text { protein }\end{array}$ & Hepatoma cell & $\begin{array}{l}\text { Hepatic stellate } \\
\text { cell }\end{array}$ & Influence hepatic microenvironment & [41] \\
\hline & DNA & CHB patients & $\begin{array}{l}\text { Naïve hepatocyte } \\
\text { cell lines }\end{array}$ & Transmit HBV to primary hepatocytes & {$[37]$} \\
\hline \multirow[t]{9}{*}{$\mathrm{HCV}$} & RNA & HCV-infected hepatocytes & Monocyte & $\begin{array}{l}\text { Promote macrophage polarization and circulating } \\
\text { fibrocyte generation }\end{array}$ & {$[86]$} \\
\hline & RNA & Hepatocyte & $\mathrm{pDCs}$ & Activate pDCs and promote $\mathrm{HCV}$ infection & {$[82]$} \\
\hline & RNA & $\begin{array}{l}\text { Sera of HCV- infected } \\
\text { patients/hepatocytes }\end{array}$ & Hepatocytes & Transmit HCV transfection & {$[115]$} \\
\hline & RNA & Hepatocyte & $\mathrm{pDC}$ & Activate innate immune and type I IFN production & [116] \\
\hline & RNA & Hepatocyte & DC & DCs mature to induce NK and CTL activation & {$[80]$} \\
\hline & RNA & Hepatocyte & $\mathrm{pDC}$ & Trigger innate immunity & {$[82]$} \\
\hline & RNA & Hepatocyte & $\begin{array}{l}\text { Monocytic } \\
\text { myeloid cell }\end{array}$ & $\begin{array}{l}\text { Trigger the expansion of myeloid-derived suppressor } \\
\text { cells }\end{array}$ & {$[117]$} \\
\hline & dsRNA & Hepatocyte & Hepatocyte & Reduce the activation of toll-like receptor 3 & [97] \\
\hline & RNA & Hepatoma cell & Hepatoma cell & $\begin{array}{l}\text { Transmit productive } \mathrm{HCV} \text { infection and are partially } \\
\text { resistant to antibody neutralization }\end{array}$ & {$[45]$} \\
\hline HAV & eHAV & Hepatocyte & $\mathrm{pDC}$ & Produce substantial IFN- $\alpha$ to active innate immune & [79] \\
\hline \multirow[t]{2}{*}{ HEV } & RNA & Hepatoma cell & - & Escape from the immune response & [118] \\
\hline & $\begin{array}{l}\text { viral ORF3 } \\
\text { protein }\end{array}$ & Hepatoma cell & Hepatoma cell & Modulate the host response & {$[58]$} \\
\hline
\end{tabular}

Exosome containing viral components (protein, nucleic acids) are categorized with their types, donor cells, recipient cells, and biological function as listed

infected primary hepatocytes [40]. Moreover, both HBx mRNA and protein were found to be packaged in exosomal cargos, protecting them from the host nuclease attack [41].

\section{Exosome mediates $\mathrm{HCV}$ replication and transition}

$\mathrm{HCV}$ is another major type of hepatitis virus infecting 170 million people worldwide. The genome of $\mathrm{HCV}$, a positive single-stranded RNA, encodes essential components for viral particle formation including three structural proteins (core, E1, and E1) and seven nonstructural proteins (p7, NS2, NS3, NS4A, NS4B, NS5A, and NS5B) after entry into the hepatocytes [42, 43]. The positive-strand RNA serves as a template to synthesize the replication intermediates as well, particularly the double-stranded RNA (dsRNA); then, the synthetic negative-strand RNA replicates to synthesize a bunch of progeny genomic RNA. With the help of cellular apolipoproteins, a replicase complex is assembled within vesicle-like membranes, and ultimately formatted into cell-accessible viral particles [44].

Similarly, exosomes derived from HCV-infected hepatocytes are observed to contain complete or subgenomic HCV RNA, validated in both laboratory models and clinical samples from HCV-infected patients [45, 46]. Depletion of ESCRT component led to a significant reduction in exosome production, sequentially resulting in decreased HCV replication [47]. The replication-competent genomic RNAs in exosomes are crucial in HCV secretion and cell to cell transmission [48]. Interestingly, the secretion of HCVcontaining exosomes requires a tetraspanin, CD81, which facilitating the viral attachment and fusion by mediating the recognition to HCV envelope glycoprotein E2 [49, 50]. In the absence of CD81, HCV envelope proteins are almost completely retained in the endoplasmic reticulum [51]. Correspondingly, treatment with U18666A, an MVB transport inhibitor, led to an increased viral particle accumulation in cells but less secretion, indicating that the 
endosomal pathway is involved in $\mathrm{HCV}$ particle release [52].

\section{Exosome mediates HAV/HEV replication and transition}

HAV and HEV have also been reported to egress virus particles in an exosome-mediated way [53, 54]. HAV is a type of picornavirus lacking envelope; capsid formation of HAV relies on ESCRT III-dependent process [55]. HAV released from cells is cloaked in host-derived membranes, which facilitates their escape from neutralizing antibodies and promotes virus spread [56]. The phosphatidylserine receptor, hepatitis A virus cellular receptor 1 (HAVCR1), and the cholesterol transporter, Niemann-Pick disease type $\mathrm{C} 1$ (NPC1) participate in cargo delivery of exosomes from HAV-infected cells which contains HAV RNA to cytoplasm by endocytosis [57].

Similarly, HEV existing in the blood is membrane-associated and in a quasi-enveloped form compared with the naked wildtype HEV. As particles released from infected cells via the exosomal pathway, the lipid membrane of HEV capsids resembles the membrane of exosomes [58]. Rab5 and Rab7, two proteins regulating exosome production and secretion, are required for enveloped HEV transportation while blocking endosomal acidification abrogates HEV production and infectivity [59].

\section{Exosomes participate in hepatitis virus-related liver diseases}

Uncontrolled viruses accumulate risk of fibrosis, cirrhosis and carcinogenic process consequently. Exosome-mediated viral-transportation helps to circumvent the supervision of immune system and stimulate morbigenous pathways. In addition, an exosome is required in the transition of multiple phlogogenic or oncogenic factors. In hepatitis virusinduced inflammatory state, damaged parenchymal hepatic cells secrete inflammatory factors, such as platelet-derived growth factor (PDGF) and transforming growth factor- $\beta$ (TGF $\beta$ ), resulting in the activation of hepatic stellate cells (HSCs) from quiescent condition to initiate the fibrogenic stage. The most significant symbol of hepatic fibrosis is intrahepatic connective tissue dysplasia and a massive diffuse extracellular matrix (ECM) deposition, which is labeled with the upregulation of collagen, laminin, $\alpha$ smooth muscle actin ( $\alpha$-SMA), and so on. Growing evidences have clarified that exosomes from hepatitis virusinfected hepatocytes regulate their contact with HSCs [60]. Exosomes derived from $\mathrm{HCV}$-infected hepatocytes contain miR-19, which are then directly internalized to modulate SOCS-STAT3 axis and upregulate ECM factors in HSC [61]. TGF- $\beta$ is recognized as an effector involved in the activation of fibrosis through increasing SMAD-dependent transcription. TGF- $\beta$, which is hardly expressed in normal conditions, is found to be increased when exposed to hepatitis viruses or even viral elements [62]. miR-192 is also found in exosomes from HCV-infected hepatocytes, which is transferred to HSCs to upregulate TGF- $\beta 1$, resulting in the activation and transdifferentiating of HSCs into myofibroblasts [63]. TGF- $\beta 2$ released from HCV-infected cells is passed on to HSCs in an exosome-mediated autocrine manner, leading to an increase in fibrogenic responses in the adjacent HSCs [64].

Persistent active viral replication is responsible for irreversible tumorigenic progression, indicating HBV- or HCV-related HCC. During HBV infection, factors accounting for hepatocarcinogenesis include the integration of HBV DNA, the oncoprotein $\mathrm{HBx}$ and $\mathrm{preS} / \mathrm{S}$, and HBV-inflicted DNA damage due to hepatocellular regeneration [65]. Exosomes carrying these oncogenic elements may activate some carcinogenic pathways like the classical phosphatidylinositol 3-kinase (PI3K) or mitogen-activated protein kinase (MAPK) pathways to trigger the carcinogenesis process in target cells. Moreover, HCC-derived exosomes possess distinct contents, which account for tumor malignancy, metastasis, immune escape, and drug resistance. Epithelial-mesenchymal transition (EMT) process is positively correlated with the degree of tumor metastasis to a significant extent; tumor cells undergoing EMT can release exosomes containing components beneficial for tumor transition. miRNA is a type of endogenous non-coding RNA with a small size (19-23 nts), which competitively modulates its target gene expression by silencing transcription. A set of miRNAs targeting multiple oncogenes or tumor suppressor genes (hsa-miR-125b-5p, hsa-miR-374a-5p, hsa-miR-24-3p, hsa-miR-200b-3p, and hsa-miR-21-5p) are statistically upregulated in the exosomes from EMT-hepatic cells [66].

\section{Exosomes in the interplay between hepatitis viruses and the immune system}

The complicated microenvironment endows exosomes with more paradoxical characters to the virus in liver: friend and foe. Apart from broadening the transmission of hepatitis viruses, particles carrying increased viral antigens also facilitate their immunogenicity and elicit amplified immune reaction concomitantly [67]. Normally, hepatitis viruses can be recognized by various immune cells through the pattern recognition receptors (PRRs), ensuing the activation of the innate immune response. Effective innate immune responses to viral invasion are necessary in viral pathogenesis or clearance, which mainly occur in natural killer (NK) cells, dendritic cells (DCs), and T cells via the activation of interferon-related signaling pathways (Fig. 2) 


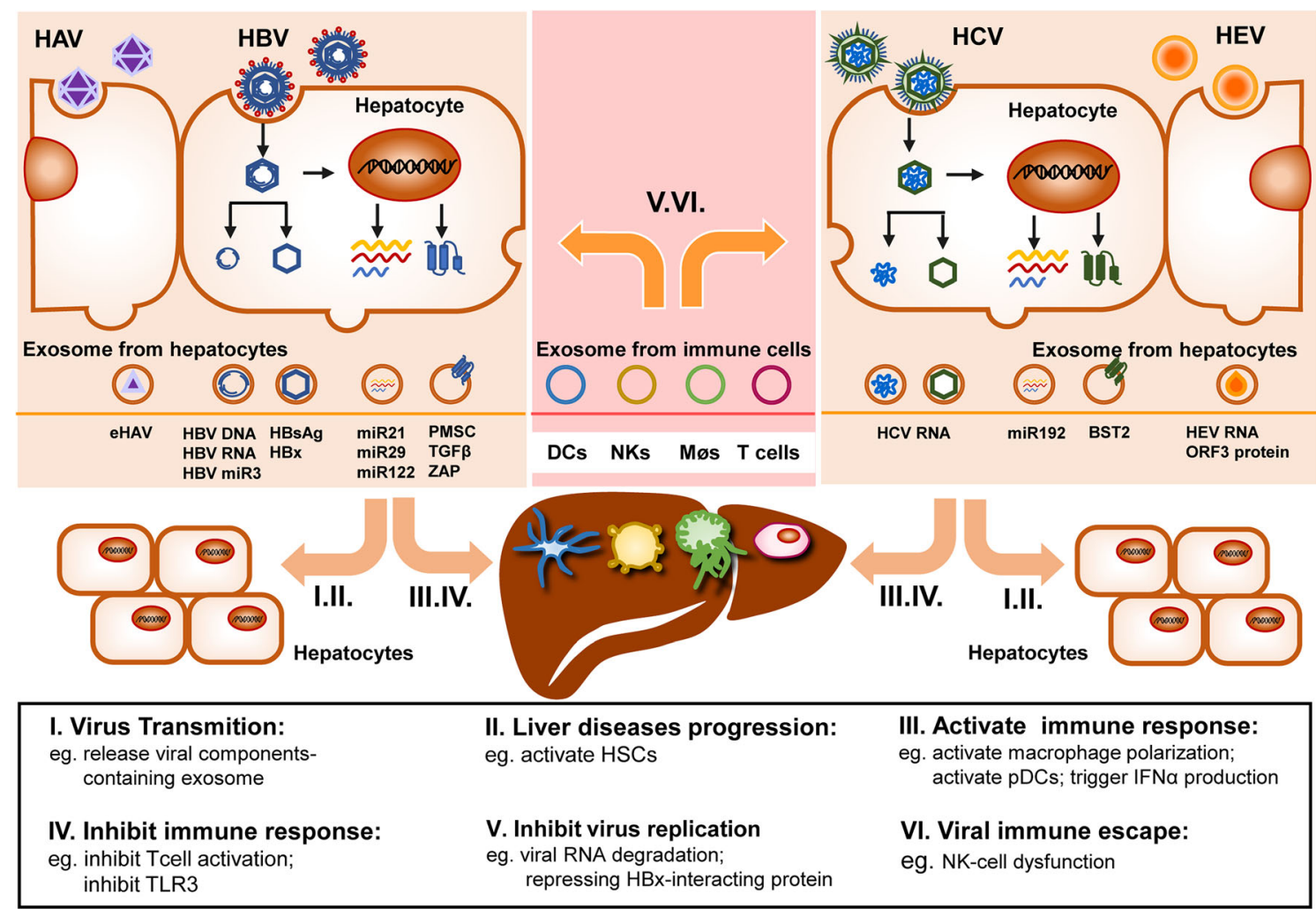

Fig. 2 Exosome-mediated immune evasion of hepatitis viruses. Different origins and contents endow exosome with variable function: exosomes from infected hepatocytes can transmit infective viral component, hiding them from the immune system (I, IV); exosome containing specific product from infected hepatocytes can induce

[68]. But in some conditions, exosomes can also contribute to immune escape and make the immune interaction more elusive, especially in this immune privilege organ: "liver".

\section{Immune cell-derived exosomes regulate the host response to hepatitis virus invasion}

NK cell is a type of cytotoxic lymphocyte implementing immunological surveillance in the non-specific immune response of the host via its cytotoxic function or secretion of specific antiviral immune cytokines. The biofunction of NK cell is complex. An essential immune-activating receptor, natural killer group 2 member D (NKG2D), in NK cell regulates its antiviral process predominantly. NKG2D combines with its ligands to distinguish abnormal cells and transduce the anti-viral signal. Proteins carried on the exosome from morbid cells, such as HSP70, can directly activate the cytolytic and migratory capacity of NK cells [69]. Exosomes released from HBV-infected hepatocytes contain HBV nucleic acids, which can stimulate MyD88, Toll-IL-1 receptor-containing adaptor molecule-1 (TICAM-1), and mitochondrial antiviral signaling (MAVS) -dependent pathways to induce NKG2D ligand expression, immune response and liver diseases progression in target cells (II, III); almost exosome released from immune cells transmits antiviral factors, while immune-inhibitory factors can also be found inside (V, VI)

and evoke NK cells [70]. Both resting and activated NKcells can release exosomes displaying immune homeostatic activities [71]. A sets of typical NK cell markers and antiviral proteins have been found to be expressed on NK cell-derived exosomes, such as perforin and natural cytotoxicity receptors (NCRs, i.e., NKp30, NKp46, and NKp44) [72, 73].

DCs are the most effective antigen-presenting cells when encountering viral attack, and stimulate the initial T cell activation or NK function through the Toll/IL-1R domain-containing adaptor-inducing IFN- $\beta$ (TRIF) pathway $[74,75]$. Recognition of hepatitis virus is the first step to induce DC maturation and produce endogenous type I interferon that initiates and triggers the innate immune responses [76, 77]. HBV DNA and HBsAg can be recognized by TLR9 on DCs, and then be processed by functional $\mathrm{T}$ cells [78]. HCV or HAV are sensed by plasmacytoid DCs (pDCs) for peak immune response [79]. Exosomes containing HCV RNA purified from the supernatant of HCV-infected hepatocytes led to TLR3-mediated DC maturation [80]. Furthermore, DC-derived exosomes, named as DEX, which contain the surface expression of functional major histocompatibility complex (MHC)- 
peptide complexes, are under trial for the feasibility of DCbased immune therapy [81]. Previous research has explored that when countering viral infection, genes related to exosome trafficking, such as Charged Multivesicular Body Protein 4B (CHMP4B), TSG101, and Annexin A2 (ANXA2) are activated in pDCs [82]. DEX harboring IL15R $\alpha$ is considered to boost NK and T cell immune responses via IFN $\gamma$ secretion [83]. In phase II clinical trial, IFN- $\gamma$-containing DEX was observed to upregulate NKp30 ligand B cell lymphoma 2 (Bcl2)-associated athanogene cochaperone 6 (BAG6) and MHC class II level in patients bearing inoperable non-small cell lung cancer without tumor progression, who achieved longer progression-free survival compared to the control groups [84].

Macrophage is a type of white blood cell that can digest cellular debris or other foreign substances and produce inflammatory cytokines. The liver-resident macrophages are defined as Kupffer cells [85]. During hepatitis virus infection, TLRs are crucial in mediating monocyte differentiation and macrophage polarization [86]. Macrophagederived exosomes can access the hepatocytes through $\mathrm{T}$ cell immunoglobulin and mucin receptor 1 (TIM-1), and then deliver IFN- $\alpha$-induced anti-HBV activity [87]. In $\mathrm{HCV}$ infection, the number of activated macrophages increased as well as the TNF secretion. Activated macrophages also conferred anti-HCV activity to hepatocytes via the consequent release of exosomes containing anti-HCV miRNA-29 family members $[88,89]$.

\section{Hepatitis virus achieves immune escape via exosomes}

Apart from using the ESCRT machinery to assemble and transmit virions, these tiny but proficient viruses also rely on exosomes to puzzle and escape the host immune defense. Normally, these pathogens could stimulate the maturation of DCs, T cells, and other immune effective cells, which correspondingly secrete inflammatory factors to inhibit different stages of viral replication or directly eliminate the infected hepatocytes [90]. However, when endogenous immune system was insufficient for viral clearance, it would lead to chronic infection and the risk of end-stage liver diseases in some cases. Although the viral exosomes enhance the visibility of the viruses to the innate interferon pathway, recent studies have demonstrated that the hepatitis virus can escape the host immune defense by impairing the DC function [91]. In patients with chronic HBV infection, both the quantity and function of pre-DCs or mature DCs are impaired [92, 93].

Stimulating a set of immune inhibitory factors is another approach for hepatitis viruses to achieve immune escape. Previous research has shown that HBV infection could upregulate representative immunosuppressive factors, such as TGF- $\beta 1$, thereby blocking NKG2D and $2 \mathrm{~B} 4$ activity resulting in NK-cell dysfunction [94]. Consistent with this finding, NK cells were also functionally impaired by persistent HBV-positive exosomes with decreased cell cytotoxicity and IFN- $\gamma$ production [39]. Exosomes produced by HBV-infected cells were found to suppress the retinoic acid-inducible gene I (RIG-I) on NK cells, which dampened the nuclear factor $\kappa \mathrm{B}(\mathrm{NF}-\kappa \mathrm{B})$ and $\mathrm{p} 38$ mitogen-activated protein kinase pathways. An ISG-coding protein, IFITM2, was found on exosomes secreted by HBV-infected hepatocytes; they were enrolled in the negative feedback regulation of the IFN pathway by attenuating the IRF3/TBK1-mediated IFN pathway after targeting DCs [95]. Besides, HBV facilitates the externalization of some antiviral proteins, like APOBEC $3 \mathrm{G}$, by assembling them into exosomes, followed by the corresponding decrease in the intracellular level of the restriction proteins [96].

Similar immune escape mechanisms occur in HCV-infected cells. HCV-infected cells substantially secrete exosomes containing HCV RNA. These exosomes target the surrounding cells to reduce the activation of toll-like receptor 3 (TLR3) and interfere with the anti-viral ISG activation. Blocking exosome secretion by GW4869 reanimated the TLR3-related pathway and elicited subsequent antiviral response [97]. These HCV RNA-containing exosomes were found to be associated with $\mathrm{T}$ cell activation by inhibiting IL-2 release and CD69 expression after co-culturing [98].

\section{Exosomes serve as promising therapeutic strategy}

\section{Exosomal biomarkers in viral hepatitis and related liver diseases}

There is a tight link between hepatitis infection with the hepatic histopathological change, even tumorigenesis. However, current imaging techniques, including ultrasonography and magnetic resonance are still insufficient for precise diagnosis in patients with asymptomatic earlystage HCC, or prediction of therapeutic outcomes. Therefore, biomarkers with both accuracy and accessibility are urgently needed. Now that heterologous exosomes can carry proteins or nucleic acid species of originated cells, identifying distinct disease-related biomarkers might contribute towards the identification of risk patients for the outbreak even before the initial symptoms [99]. Updating researches on EVs and their specific signatures provide a theoretical basis and guide future clinical investigation (Table 2).

In recent years, a set of microRNAs (miRNAs) are found to be greatly involved in hepatitis virus replication and transition. Hepatitis virus infection affects the miRNA 
Table2 Hepatitis viruses-related exosome involved in liver environment

\begin{tabular}{|c|c|c|c|c|}
\hline Biomarker & Donor cell & $\begin{array}{l}\text { Recipient } \\
\text { cell }\end{array}$ & Function & References \\
\hline $\begin{array}{l}\text { PMSC1/2 } \\
\text { PMSD1/7/14 }\end{array}$ & Hepatoma cell & Monocyte & Induce production of pro-inflammatory molecules & {$[101]$} \\
\hline DDX60 & Hepatocyte & NK cells & Mediated cytoplasmic viral HBV RNA degradation & {$[70]$} \\
\hline $\begin{array}{l}\text { miR-192/92a/ } \\
\quad 200 \mathrm{~b}\end{array}$ & Plasma & $\mathrm{HSC}$ & Down-regulated during $\mathrm{HSC}$ activation & [119] \\
\hline TGF- $\beta$ & Hepatoma cell & $\begin{array}{l}\text { Hepatoma } \\
\text { cell }\end{array}$ & Induce TGF- $\beta$ mediated suppression of HBV & {$[120]$} \\
\hline HBV-miR-3 & Hepatocyte & Hepatocyte & Attenuate $\mathrm{HBV}$ replication and Repress $\mathrm{HBsAg} / \mathrm{HBe} A g$ & {$[121]$} \\
\hline miR-122 & Hepatoma cell & $\begin{array}{l}\text { Hepatoma } \\
\text { cell }\end{array}$ & Inhibit $\mathrm{HBV}$ expression & [122] \\
\hline miR-21/ 29 & Hepatocyte & NK cells & Inhibit NK cells and suppress HBV proliferation & {$[104,123]$} \\
\hline ZAP & Hepatocyte & Hepatocyte & Degrade HBV pgRNA substrate and control HBV replication & [124] \\
\hline OSTM1 & Hepatoma cell & $\begin{array}{l}\text { Hepatoma } \\
\text { cell }\end{array}$ & $\begin{array}{l}\text { Downregulate HBV replication through posttranscriptional regulation or } \\
\text { RNA stability }\end{array}$ & {$[125]$} \\
\hline miRNA204 & Hepatoma cell & $\begin{array}{l}\text { Hepatoma } \\
\text { cell }\end{array}$ & Suppressive effect on HBV replication & [126] \\
\hline Ski2 & Hepatocyte & Hepatocyte & Negatively regulate HBx mRNA, suppress HBV replication & {$[127]$} \\
\hline miR-15b & Hepatocyte & Hepatocyte & Promote HBV replication by aiding HBV enhancer I activity HNF- $1 \alpha$ & [128] \\
\hline APOE & Hepatocyte & Hepatocyte & Promote hepatitis B virus infection and production & [129] \\
\hline APOBEC3G & Hepatocyte & Hepatocyte & Inhibits HBV replication & {$[130]$} \\
\hline IFITM2 & Hepatocyte & Dendritic cell & $\begin{array}{l}\text { Inhibit IFN } \alpha \text { pathway activation and block anti-HBV efficacy of exogenous } \\
\text { IFN } \alpha\end{array}$ & {$[95]$} \\
\hline $\mathrm{CD} 81+$ & Hepatocyte & Macrophage & Carry HCV particles and establish persistent infection & [131] \\
\hline $\begin{array}{l}\text { Ago2- } \\
\text { miR122- } \\
\text { HSP90 }\end{array}$ & $\begin{array}{l}\text { Serum or } \\
\text { Hepatoma cell }\end{array}$ & $\begin{array}{l}\text { Hepatoma } \\
\text { cell }\end{array}$ & Enhance HCV RNA stability and viral replication & {$[115]$} \\
\hline $\operatorname{miR} 122$ & Hepatoma cell & $\begin{array}{l}\text { Hepatoma } \\
\text { cell }\end{array}$ & Targets CCNG1 and NDRG3 to inhibit viral replication & {$[132]$} \\
\hline IFITM1 & Hepatocyte & Hepatocyte & Interruption of viral coreceptor function & [133] \\
\hline GAL-9 & Monocytes & $\mathrm{T}$ cell & Inhibit $\mathrm{T}$ cells in $\mathrm{HCV}$ infection & [134] \\
\hline ISG & LSEC & Hepatocyte & Inhibit HCV replication & [135] \\
\hline miR-192 & $\begin{array}{l}\text { HCV-replicating } \\
\text { hepatocyte }\end{array}$ & $\mathrm{HSC}$ & Activation and transdifferentiation of HSCs into myofibroblasts & {$[63]$} \\
\hline $\operatorname{miR}-19 \mathrm{a}$ & Hepatocyte & $\begin{array}{l}\text { Hepatic } \\
\text { stellate } \\
\text { cell }\end{array}$ & Activate HSC by modulating the SOCS-STAT3 axis & {$[61]$} \\
\hline UCHL1 & $\begin{array}{l}\text { HCV-infected } \\
\text { hepatocyte }\end{array}$ & HSC & Stimulate HSCs activation through JNK phosphorylation & [136] \\
\hline miR-501 & Hepatoma cell & $\begin{array}{l}\text { Hepatoma } \\
\text { cell }\end{array}$ & Activate HBV replication by repressing HBx-interacting protein (HBXIP) & [137] \\
\hline $\operatorname{miR}-125 b$ & Hepatoma cell & $\begin{array}{l}\text { Hepatoma } \\
\text { cell }\end{array}$ & $\begin{array}{l}\text { Inhibit } \mathrm{HBV} \text { DNA intermediates and the secretion of } \mathrm{HBsAg} \text { and } \mathrm{HBeAg} \\
\text { by targeted repression of SCNN1A }\end{array}$ & [138] \\
\hline BST2 & Hepatoma cell & Hepatocyte & Inhibit $\mathrm{HCV}$ assembly or release & [139] \\
\hline miR-29 & Macrophage & Hepatocyte & Activate macrophage and inhibit $\mathrm{HCV}$ replication & [89] \\
\hline
\end{tabular}

Exosome secreted from different types of cell under hepatitis virus infection are summarized, which are labelled with corresponding donor cell, recipient cell and biological function

levels and proteins in EVs released from virus-infected cells that transport from tissue to serum to regulate the host innate immune system [100, 101]. Expression of miRNA clusters significantly differed in the tissues of HBV- and 
HCV-infected individuals, as well as in the exosomes [102]. For example, either HBV infection or HBX overexpression could induce miR-21 and miR-29 expression in HCC cell lines, followed by a simultaneous increase of exosomal miR-21 and miR-29 levels [70, 103]. miR-21 and miR-29 directly target IL-12 subunits to reduce IL-12, a heterodimeric cytokine secreted by DCs or macrophages to activate NK cells, indicating that HBV counteracts the host innate immune responses by inducing exosomal miR-21 and miR-29 to attenuate the IL-12 production [104]. Besides, increased exosomal miR-21 is more frequently observed in HBV-related cirrhosis and HCC patients, and may act as a promising biomarker in the diagnosis of earlystage HCC [105].

In contrast with morbigenous role in HBV infection, exosomal miR-29 exerts an anti-viral effect during HCV infection. In HCV-infected individuals, exosomes released from macrophages were found to contain miR-29 family members, while inhibiting miR-29 led to the direct restoration of HCV replication [89]. Further analytical studies showed that HCV-induced miR-122 levels varied among different $\mathrm{HCV}$ genotypes. In addition, miR-122 levels in the serum and exosomes were both higher in patients that achieved SVR than that in patients who did not achieve SVR, indicating that the serum and exosome miR-122 might reflect viral hepatitis therapeutic efficacy [106]. These observations suggest that distinct exosomal contents are closely associated with diverse disease conditions or viral status, and their roles differ with different pathogen infection.

\section{Exosome is a potential therapeutic tool in hepatitis virus-associated liver diseases}

Exosome has an excellent therapeutic application in hepatitis virus infection due to its carrying capacity, self-toleration, bio-safety, resistance to RNases and proteases [107]. Engineered exosomes loaded with HBV antigens can be internalized by antigen-presenting cells, act as a decoy to induce cross-priming and antigen-specific cytotoxic T lymphocyte (CTL) immunity [108]. Uploading HCV NS3 on exosomes resulted in the successful activation of $\mathrm{CD}^{+} \mathrm{T}$ cells via DCs [109]. These findings promote the optimization of exosome-based anti-hepatitis virus agents for both curative and economic consideration, even though $\mathrm{HCV}$ is curable with DAAs.

Artificial exosomes can also serve as ideal vehicles for therapeutic protein, nucleic acid, and drug delivery based on the nano perforation technique. For instance, the CRISPR/Cas9 system is an accurate genomic editing approach, guided by a short gRNA sequence that attaches (binds) to a specific target DNA sequence. The functional components of gRNA and Cas9 protein have been validated to be loaded into the exosome, supporting to transfer the genetic editing effect. Naturally produced endogenous exosomes have been successfully used to deliver the functional Cas9 and HBV-specific gRNA to cut HBV DNA transfected in Huh7 cells [110].

Exosome derived from specific tumor cells (TEX) and immune cells are promising therapeutic materials due to their direct or indirect immune-regulatory effect. Exosomes secreted from umbilical mesenchymal stem cells (uMSCs) were found to inhibit $\mathrm{HCV}$ infection in vitro, especially viral replication, with low cell toxicity [111]. TEX-pulsed DCs (DC-TEX) induce antitumor responses and change the tumor microenvironment by decreasing regulatory $\mathrm{T}$ cell (Treg) accumulation in the tumor tissue [112]. DEX is another therapeutic candidate as a cell-free immune vaccine in HCC treatment. DCs enriched with AFP have been shown to elicit strong antigen-specific immune responses, retarded tumor growth, and significantly prolonged survival rates in an HCC model [113].

\section{Conclusion}

Acknowledged with the remarkable role in cell-cell communication, exosomes have been shown to play a role in the life cycle of hepatitis viruses and affect the pathogenesis of viral hepatitis. Exosomes containing viral components directly enhance viral infection by accelerating viral transmission to uninfected cells. Hepatitis viruses cloak their full-length or fragile hereditary elements into exosome particles, thereby becoming invisible to the host immune system. These autologous membrane structures facilitate viral transmission by protecting these viruses from neutralizing antibodies and assisting their dissemination within the host, thus providing a basis for persistent infection. In this review, the dual roles of exosomes in viral hepatitis replication and immune response is summarized. Further studies are needed for clarifying the exosomal content and the biological function of exosomes in viral hepatitis, which will help better understand the pathogenesis, provide reliable predictive factors for prognosis, and aid in the development of novel therapeutic strategies.

Acknowledgements We are very appreciated to Professor Lungji Chang of University of Electronic Science and Technology of China for valuable discussion.

Funding 1. ZYGX2020KYQD002, The fundamental research funds for the central universities. 2. 2018ZX10715003, Major national science and technology projects of "Prevention and treatment of AIDS, viral hepatitis and other infectious diseases". 3. ZYGD20009, 1.3.5 Project for disciplines of excellence, West China Hospital, Sichuan University. 4. ZYJC18008, 1.3.5 Project for disciplines of excellence, West China Hospital, Sichuan University. 5. 2021YFH0187, Sichuan Science and Technology Program. 


\section{Compliance with ethical standards}

Conflict of interest All authors declare that there is no any conflict of interest.

Open Access This article is licensed under a Creative Commons Attribution 4.0 International License, which permits use, sharing, adaptation, distribution and reproduction in any medium or format, as long as you give appropriate credit to the original author(s) and the source, provide a link to the Creative Commons licence, and indicate if changes were made. The images or other third party material in this article are included in the article's Creative Commons licence, unless indicated otherwise in a credit line to the material. If material is not included in the article's Creative Commons licence and your intended use is not permitted by statutory regulation or exceeds the permitted use, you will need to obtain permission directly from the copyright holder. To view a copy of this licence, visit http://creativecommons. org/licenses/by/4.0/.

\section{References}

1. Maticic M, Lombardi A, Mondelli MU, et al. Elimination of hepatitis C in Europe: can WHO targets be achieved? Clin Microbiol Infect. 2020;26:818-23.

2. Lanini S, Pisapia R, Capobianchi MR, et al. Global epidemiology of viral hepatitis and national needs for complete control. Expert Rev Anti Infect Ther. 2018;16:625-39.

3. Fanning GC, Zoulim F, Hou J, et al. Therapeutic strategies for hepatitis B virus infection: towards a cure. Nat Rev Drug Discov. 2019;18:827-44.

4. Miao Z, Xie Z, Miao J, et al. Regulated entry of hepatitis C virus into hepatocytes. Viruses. 2017;9:100.

5. Douam F, Lavillette D, Cosset FL. The mechanism of HCV entry into host cells. Prog Mol Biol Transl Sci. 2015;129:63-107.

6. Ringehan M, McKeating JA, Protzer U. Viral hepatitis and liver cancer. Philos Trans R Soc Lond Ser B Biol Sci. 2017;372:20160274.

7. Li S, Li S, Wu S, et al. Exosomes modulate the viral replication and host immune responses in HBV infection. Biomed Res Int. 2019;2019:2103943.

8. Johnstone RM, Adam M, Hammond JR, et al. Vesicle formation during reticulocyte maturation. Association of plasma membrane activities with released vesicles (exosomes). J Biol Chem. 1987;262:9412-20.

9. Kowal J, Tkach M, Thery C. Biogenesis and secretion of exosomes. Curr Opin Cell Biol. 2014;29:116-25.

10. Mathivanan S, Lim JW, Tauro BJ, et al. Proteomics analysis of A33 immunoaffinity-purified exosomes released from the human colon tumor cell line LIM1215 reveals a tissue-specific protein signature. Mol Cell Proteomic MCP. 2010;9:197-208.

11. Chatellard-Causse C, Blot B, Cristina N, et al. Alix (ALG-2interacting protein $\mathrm{X}$ ), a protein involved in apoptosis, binds to endophilins and induces cytoplasmic vacuolization. J Biol Chem. 2002;277:29108-15.

12. Pols MS, Klumperman J. Trafficking and function of the tetraspanin CD63. Exp Cell Res. 2009;315:1584-92.

13. Thery C, Boussac M, Veron P, et al. Proteomic analysis of dendritic cell-derived exosomes: a secreted subcellular compartment distinct from apoptotic vesicles. J Immunol. 2001;166:7309-18.

14. Subra C, Laulagnier K, Perret B, et al. Exosome lipidomics unravels lipid sorting at the level of multivesicular bodies. Biochimie. 2007;89:205-12.
15. Hirsova P, Ibrahim SH, Krishnan A, et al. Lipid-induced signaling causes release of inflammatory extracellular vesicles from hepatocytes. Gastroenterology. 2016;150:956-67.

16. Raiborg C, Stenmark H. The ESCRT machinery in endosomal sorting of ubiquitylated membrane proteins. Nature. 2009;458:445-52.

17. Hanson PI, Cashikar A. Multivesicular body morphogenesis. Annu Rev Cell Dev Biol. 2012;28:337-62.

18. Williams RL, Urbe S. The emerging shape of the ESCRT machinery. Nat Rev Mol Cell Biol. 2007;8:355-68.

19. Strauss K, Goebel C, Runz H, et al. Exosome secretion ameliorates lysosomal storage of cholesterol in Niemann-Pick type C disease. J Biol Chem. 2010;285:26279-88.

20. Kobayashi T, Beuchat MH, Lindsay M, et al. Late endosomal membranes rich in lysobisphosphatidic acid regulate cholesterol transport. Nat Cell Biol. 1999;1:113-8.

21. Gruenberg J. Life in the lumen: the multivesicular endosome. Traffic. 2020;21:76-93.

22. Trajkovic K, Hsu C, Chiantia S, et al. Ceramide triggers budding of exosome vesicles into multivesicular endosomes. Science. 2008;319:1244-7.

23. Savina A, Furlan M, Vidal M, et al. Exosome release is regulated by a calcium-dependent mechanism in K562 cells. J Biol Chem. 2003;278:20083-90.

24. Falcon V, Acosta-Rivero N, Gonzalez S, et al. Ultrastructural and biochemical basis for hepatitis $\mathrm{C}$ virus morphogenesis. Virus Genes. 2017;53:151-64.

25. Bandopadhyay M, Bharadwaj M. Exosomal miRNAs in hepatitis B virus related liver disease: a new hope for biomarker. Gut Pathog. 2020;12:23.

26. Schorey JS, Cheng Y, Singh PP, et al. Exosomes and other extracellular vesicles in host-pathogen interactions. EMBO Rep. 2015;16:24-43.

27. Vojtech L, Woo S, Hughes S, et al. Exosomes in human semen carry a distinctive repertoire of small non-coding RNAs with potential regulatory functions. Nucleic Acids Res. 2014;42:7290-304.

28. Anderson MR, Kashanchi F, Jacobson S. Exosomes in Viral Disease. Neurother J Am Soc Exp NeuroTher. 2016;13:535-46.

29. Wang J, Huang H, Liu Y, et al. HBV genome and life cycle. Adv Exp Med Biol. 2020;1179:17-37.

30. Rodriguez-Frias F, Jardi R. Virologia molecular del virus de la hepatitis B [Molecular virology of the hepatitis B virus]. Enferm Infecc Microbiol Clin. 2008;26(Suppl 7):2-10.

31. Karayiannis P. Hepatitis B virus: virology, molecular biology, life cycle and intrahepatic spread. Hepatol Int. 2017;11:500-8.

32. Seeger C, Mason WS. Hepatitis B virus biology. Microbiol Mol Biol Rev MMBR. 2000;64:51-68.

33. Xie N, Huang K, Zhang $\mathrm{T}$, et al. Comprehensive proteomic analysis of host cell lipid rafts modified by HBV infection. J Proteomics. 2012;75:725-39.

34. Jiang B, Himmelsbach K, Ren H, et al. Subviral hepatitis B virus filaments, like infectious viral particles, are released via multivesicular bodies. J Virol. 2015;90:3330-41.

35. Novellino L, Rossi RL, Bonino F, et al. Circulating hepatitis B surface antigen particles carry hepatocellular microRNAs. PLoS ONE. 2012;7:e31952.

36. Zhao X, Wu Y, Duan J, et al. Quantitative proteomic analysis of exosome protein content changes induced by hepatitis B virus in Huh-7 cells using SILAC labeling and LC-MS/MS. J Proteome Res. 2014;13:5391-402.

37. Sukriti S, Choudhary MC, Maras JS, et al. Extracellular vesicles from hepatitis B patients serve as reservoir of hepatitis B virus DNA. J Viral Hepat. 2019;26:211-4. 
38. Watanabe T, Sorensen EM, Naito A, et al. Involvement of host cellular multivesicular body functions in hepatitis B virus budding. Proc Natl Acad Sci USA. 2007;104:10205-10.

39. Yang Y, Han Q, Hou Z, et al. Exosomes mediate hepatitis B virus (HBV) transmission and NK-cell dysfunction. Cell Mol Immunol. 2016;14:465-75.

40. Sanada T, Hirata Y, Naito Y, et al. Transmission of HBV DNA mediated by ceramide-triggered extracellular vesicles. Cell Mol Gastroenterol Hepatol. 2017;3:272-83.

41. Kapoor NR, Chadha R, Kumar S, et al. The HBx gene of hepatitis $\mathrm{B}$ virus can influence hepatic microenvironment via exosomes by transferring its mRNA and protein. Virus Res. 2017;240:166-74.

42. Moradpour D, Penin F. Hepatitis C virus proteins: from structure to function. Curr Top Microbiol Immunol. 2013;369:113-42.

43. Czaja AJ. Chronic hepatitis $\mathrm{C}$ virus infection-a disease in waiting? N Engl J Med. 1992;327:1949-50.

44. Catanese MT, Uryu K, Kopp M, et al. Ultrastructural analysis of hepatitis $\mathrm{C}$ virus particles. Proc Natl Acad Sci USA. 2013;110:9505-10.

45. Ramakrishnaiah V, Thumann C, Fofana I, et al. Exosome-mediated transmission of hepatitis $\mathrm{C}$ virus between human hepatoma Huh7.5 cells. Proc Natl Acad Sci USA. 2013;110:13109-13.

46. Karamichali E, Chihab H, Kakkanas A, et al. HCV defective genomes promote persistent infection by modulating the viral life cycle. Front Microbiol. 2018;9:2942.

47. Tamai K, Shiina M, Tanaka N, et al. Regulation of hepatitis C virus secretion by the Hrs-dependent exosomal pathway. Virology. 2012;422:377-85.

48. Zhao F, Zhao T, Deng L, et al. Visualizing the essential role of complete virion assembly machinery in efficient hepatitis $\mathrm{C}$ Virus cell-to-cell transmission by a viral infection-activated split-intein-mediated reporter system. J Virol. 2017. https://doi. org/10.1128/JVI.01720-16.

49. Masciopinto F, Giovani C, Campagnoli S, et al. Association of hepatitis $\mathrm{C}$ virus envelope proteins with exosomes. Eur J Immunol. 2004;34:2834-42.

50. Liu X, Chen N, Lin S, et al. Synthesized peptide 710-725 from HCV subtype 1a E2 glycoprotein blocks HCV infection through competitive binding of CD81. Int J Mol Med. 2016;37:836-42.

51. Liu Z, Zhang X, Yu Q, et al. Exosome-associated hepatitis C virus in cell cultures and patient plasma. Biochem Biophys Res Commun. 2014;455:218-22.

52. Elgner F, Ren H, Medvedev R, et al. The intracellular cholesterol transport inhibitor U18666A inhibits the exosome-dependent release of mature hepatitis $\mathrm{C}$ virus. $\mathrm{J}$ Virol. 2016;90:11181-96.

53. Nagashima S, Jirintai S, Takahashi M, et al. Hepatitis E virus egress depends on the exosomal pathway, with secretory exosomes derived from multivesicular bodies. J Gen Virol. 2014;95:2166-75.

54. Feng Z, Hirai-Yuki A, McKnight KL, et al. Naked viruses that aren't always naked: quasi-enveloped agents of acute hepatitis. Annu Rev Virol. 2014;1:539-60.

55. McKnight KL, Xie L, Gonzalez-Lopez O, et al. Protein composition of the hepatitis A virus quasi-envelope. Proc Natl Acad Sci USA. 2017;114:6587-92.

56. Feng Z, Hensley L, McKnight KL, et al. A pathogenic picornavirus acquires an envelope by hijacking cellular membranes. Nature. 2013;496:367-71.

57. Costafreda MI, Abbasi A, Lu H, et al. Exosome mimicry by a HAVCR1-NPC1 pathway of endosomal fusion mediates hepatitis A virus infection. Nat Microbiol. 2020;5:1096-106.

58. Nagashima S, Takahashi M, Kobayashi T, et al. Characterization of the quasi-enveloped hepatitis $\mathrm{E}$ virus particles released by the cellular exosomal pathway. J Virol. 2017. https://doi.org/ 10.1128/JVI.00822-17.

59. Yin X, Ambardekar C, Lu Y, et al. Distinct entry mechanisms for nonenveloped and quasi-enveloped hepatitis $\mathrm{E}$ viruses. J Virol. 2016;90:4232-42.

60. Seo W, Eun HS, Kim SY, et al. Exosome-mediated activation of toll-like receptor 3 in stellate cells stimulates interleukin-17 production by gammadelta $\mathrm{T}$ cells in liver fibrosis. Hepatology. 2016;64:616-31.

61. Devhare PB, Sasaki R, Shrivastava S, et al. Exosome-mediated intercellular communication between hepatitis $\mathrm{C}$ virus-infected hepatocytes and hepatic stellate cells. J Virol. 2017. https://doi. org/10.1128/JVI.00349-17.

62. Liu Y, Xu Y, Ma H, et al. Hepatitis B virus X protein amplifies TGF-beta promotion on HCC motility through down-regulating PPM1a. Oncotarget. 2016;7:33125-35.

63. Kim JH, Lee CH, Lee SW. Exosomal transmission of microRNA from HCV replicating cells stimulates transdifferentiation in hepatic stellate cells. Mol Ther Nucleic Acids. 2019;14:483-97.

64. Chida T, Ito M, Nakashima K, et al. Critical role of CREBHmediated induction of transforming growth factor beta 2 by hepatitis $\mathrm{C}$ virus infection in fibrogenic responses in hepatic stellate cells. Hepatology. 2017;66:1430-43.

65. Chen Y, Tian Z. HBV-induced immune imbalance in the development of HCC. Front Immunol. 2019;10:2048.

66. Lin Q, Zhou CR, Bai MJ, et al. Exosome-mediated miRNA delivery promotes liver cancer EMT and metastasis. Am J Transl Res. 2020;12:1080-95.

67. Pleet ML, Mathiesen A, DeMarino C, et al. Ebola VP40 in exosomes can cause immune cell dysfunction. Front Microbiol. 2016;7:1765.

68. Guo H, Jiang D, Ma D, et al. Activation of pattern recognition receptor-mediated innate immunity inhibits the replication of hepatitis B virus in human hepatocyte-derived cells. J Virol. 2009;83:847-58.

69. Radons J, Multhoff G. Immunostimulatory functions of membrane-bound and exported heat shock protein 70 . Exercise Immunol Rev. 2005;11:17-33.

70. Kouwaki T, Fukushima Y, Daito T, et al. Extracellular vesicles including exosomes regulate innate immune responses to hepatitis B virus infection. Front Immunol. 2016;7:335.

71. Wang Y, Wang W, Shen C, et al. NKG2D modulates aggravation of liver inflammation by activating $\mathrm{NK}$ cells in $\mathrm{HBV}$ infection. Sci Rep. 2017;7:88.

72. Lugini L, Cecchetti S, Huber V, et al. Immune surveillance properties of human NK cell-derived exosomes. J Immunol. 2012;189:2833-42.

73. Fais S. NK cell-released exosomes: natural nanobullets against tumors. Oncoimmunology. 2013;2:e22337.

74. Akazawa T, Ebihara T, Okuno M, et al. Antitumor NK activation induced by the toll-like receptor 3-TICAM-1 (TRIF) pathway in myeloid dendritic cells. Proc Natl Acad Sci USA. 2007;104:252-7.

75. Simhadri VR, Reiners KS, Hansen HP, et al. Dendritic cells release HLA-B-associated transcript-3 positive exosomes to regulate natural killer function. PLoS ONE. 2008;3:e3377.

76. Takahashi K, Asabe S, Wieland S, et al. Plasmacytoid dendritic cells sense hepatitis $\mathrm{C}$ virus-infected cells, produce interferon, and inhibit infection. Proc Natl Acad Sci USA. 2010;107:7431-6.

77. Pfaender S, Grabski E, Detje CN, et al. Hepatitis C virus stimulates murine CD8alpha-like dendritic cells to produce type I interferon in a TRIF-dependent manner. PLoS Pathog. 2016;12:e1005736. 
78. Ma YJ, He M, Han JA, et al. A clinical study of HBsAg-activated dendritic cells and cytokine-induced killer cells during the treatment for chronic hepatitis B. Scand J Immunol. 2013;78:387-93.

79. Feng Z, Li Y, McKnight KL, et al. Human pDCs preferentially sense enveloped hepatitis A virions. J Clin Invest. 2015;125:169-76

80. Nakai M, Oshiumi H, Funami K, et al. Interferon (IFN) and cellular immune response evoked in RNA-pattern sensing during infection with hepatitis $\mathrm{C}$ virus (HCV). Sensors. 2015; 15:27160-73.

81. Zhang B, Yin Y, Lai RC, et al. Immunotherapeutic potential of extracellular vesicles. Front Immunol. 2014;5:518.

82. Dreux M, Garaigorta U, Boyd B, et al. Short-range exosomal transfer of viral RNA from infected cells to plasmacytoid dendritic cells triggers innate immunity. Cell Host Microbe. 2012;12:558-70.

83. Viaud S, Terme M, Flament C, et al. Dendritic cell-derived exosomes promote natural killer cell activation and proliferation: a role for NKG2D ligands and IL-15Ralpha. PLoS ONE. 2009; 4:e4942.

84. Besse B, Charrier M, Lapierre V, et al. Dendritic cell-derived exosomes as maintenance immunotherapy after first line chemotherapy in NSCLC. Oncoimmunology. 2016;5:e1071008.

85. Jenne $\mathrm{CN}$, Kubes P. Immune surveillance by the liver. Nat Immunol. 2013;14:996-1006.

86. Saha B, Kodys K, Adejumo A, et al. Circulating and exosomepackaged hepatitis C single-stranded RNA induce monocyte differentiation via TLR7/8 to polarized macrophages and fibrocytes. J Immunol. 2017;198:1974-84.

87. Yao Z, Qiao Y, Li X, et al. Exosomes exploit the virus entry machinery and pathway to transmit alpha interferon-induced antiviral activity. J Virol. 2018. https://doi.org/10.1128/JVI. 01578-18.

88. Tu Z, Pierce RH, Kurtis J, et al. Hepatitis C virus core protein subverts the antiviral activities of human Kupffer cells. Gastroenterology. 2010;138:305-14.

89. Zhou Y, Wang X, Sun L, et al. Toll-like receptor 3-activated macrophages confer anti-HCV activity to hepatocytes through exosomes. FASEB J. 2016;30:4132-40.

90. Waris G, Siddiqui A. Regulatory mechanisms of viral hepatitis B and C. J Biosci. 2003;28:311-21.

91. Zimmermann M, Flechsig C, La Monica N, et al. Hepatitis C virus core protein impairs in vitro priming of specific $\mathrm{T}$ cell responses by dendritic cells and hepatocytes. J Hepatol. 2008;48:51-60.

92. van der Molen RG, Sprengers D, Biesta PJ, et al. Favorable effect of adefovir on the number and functionality of myeloid dendritic cells of patients with chronic HBV. Hepatology. 2006;44:907-14.

93. Duan XZ, Zhuang H, Wang M, et al. Decreased numbers and impaired function of circulating dendritic cell subsets in patients with chronic hepatitis B infection (R2). J Gastroenterol Hepatol. 2005;20:234-42.

94. Sun $\mathrm{C}, \mathrm{Fu} \mathrm{B}, \mathrm{Gao} \mathrm{Y}$, et al. TGF-betal down-regulation of NKG2D/DAP10 and 2B4/SAP expression on human NK cells contributes to HBV persistence. PLoS Pathog. 2012;8:e1002594.

95. Shi Y, Du L, Lv D, et al. Exosomal interferon-induced transmembrane protein 2 transmitted to dendritic cells inhibits interferon alpha pathway activation and blocks anti-hepatitis B virus efficacy of exogenous interferon alpha. Hepatology. 2019;69:2396-413.

96. Chen R, Zhao X, Wang Y, et al. Hepatitis B virus X protein is capable of down-regulating protein level of host antiviral protein APOBEC3G. Sci Rep. 2017;7:40783.
97. Grunvogel O, Colasanti O, Lee JY, et al. Secretion of hepatitis C virus replication intermediates reduces activation of toll-like receptor 3 in hepatocytes. Gastroenterology. 2018;154(2237-51):e16.

98. Bhattarai N, McLinden JH, Xiang J, et al. Conserved motifs within hepatitis C virus envelope (E2) RNA and protein independently inhibit $\mathrm{T}$ cell activation. PLoS Pathog. 2015;11:e1005183.

99. Julich H, Willms A, Lukacs-Kornek V, et al. Extracellular vesicle profiling and their use as potential disease specific biomarker. Front Immunol. 2014;5:413.

100. Kouwaki T, Okamoto M, Tsukamoto H, et al. Extracellular vesicles deliver host and virus RNA and regulate innate immune response. Int J Mol Sci. 2017;18:666.

101. Jia X, Chen J, Megger DA, et al. Label-free proteomic analysis of exosomes derived from inducible hepatitis B virus-replicating HepAD38 cell line. Mol Cell Proteomics MCP. 2017;16:S144-60.

102. Ura S, Honda M, Yamashita T, et al. Differential microRNA expression between hepatitis $\mathrm{B}$ and hepatitis $\mathrm{C}$ leading disease progression to hepatocellular carcinoma. Hepatology. 2009;49:1098-112.

103. Qiu X, Dong S, Qiao F, et al. HBx-mediated miR-21 upregulation represses tumor-suppressor function of PDCD4 in hepatocellular carcinoma. Oncogene. 2013;32:3296-305.

104. Lu TX, Munitz A, Rothenberg ME. MicroRNA-21 is up-regulated in allergic airway inflammation and regulates IL-12p35 expression. J Immunol. 2009;182:4994-5002.

105. Bao S, Zheng J, Li N, et al. Serum MicroRNA levels as a noninvasive diagnostic biomarker for the early diagnosis of hepatitis B virus-related liver fibrosis. Gut Liver. 2017;11:860-9.

106. Jiao X, Fan Z, Chen H, et al. Serum and exosomal miR-122 and miR-199a as a biomarker to predict therapeutic efficacy of hepatitis C patients. J Med Virol. 2017;89:1597-605.

107. Johnsen KB, Gudbergsson JM, Skov MN, et al. A comprehensive overview of exosomes as drug delivery vehicles-endogenous nanocarriers for targeted cancer therapy. Biochim Biophys Acta. 2014;1846:75-87.

108. Ferrantelli F, Manfredi F, Chiozzini C, et al. DNA vectors generating engineered exosomes potential CTL vaccine candidates against AIDS, hepatitis B, and tumors. Mol Biotechnol. 2018;60:773-82.

109. Anticoli S, Falcone E, Ruggieri A, Federico M. Engineered exosomes boost the HCV NS3-specific CD8 + T lymphocyte immunity in humans. Trials Vaccinol. 2016;5:105-10.

110. Chen R, Huang H, Liu H, et al. Friend or foe? Evidence indicates endogenous exosomes can deliver functional gRNA and Cas9 protein. Small. 2019;15:e1902686.

111. Qian X, Xu C, Fang S, et al. Exosomal microRNAs derived from umbilical mesenchymal stem cells inhibit hepatitis C virus infection. Stem Cells Transl Med. 2016;5:1190-203.

112. Shi S, Rao Q, Zhang C, et al. Dendritic cells pulsed with exosomes in combination with PD-1 antibody increase the efficacy of sorafenib in hepatocellular carcinoma model. Transl Oncol. 2018;11:250-8.

113. Lu Z, Zuo B, Jing R, et al. Dendritic cell-derived exosomes elicit tumor regression in autochthonous hepatocellular carcinoma mouse models. J Hepatol. 2017;67:739-48.

114. Zhao X, Sun L, Mu T, et al. An HBV-encoded miRNA activates innate immunity to restrict HBV replication. J Mol Cell Biol. 2019;12:263-76.

115. Bukong TN, Momen-Heravi F, Kodys K, et al. Exosomes from hepatitis $\mathrm{C}$ infected patients transmit $\mathrm{HCV}$ infection and contain replication competent viral RNA in complex with Ago2miR122-HSP90. PLoS Pathog. 2014;10:e1004424. 
116. Longatti $\mathrm{A}$. The dual role of exosomes in hepatitis $\mathrm{A}$ and $\mathrm{C}$ virus transmission and viral immune activation. Viruses. 2015;7:6707-15.

117. Wang L, Cao D, Wang L, et al. HCV-associated exosomes promote myeloid-derived suppressor cell expansion via inhibiting miR-124 to regulate $\mathrm{T}$ follicular cell differentiation and function. Cell Discov. 2018;4:51.

118. Chapuy-Regaud S, Dubois M, Plisson-Chastang C, et al. Characterization of the lipid envelope of exosome encapsulated HEV particles protected from the immune response. Biochimie. 2017;141:70-9.

119. Lambrecht J, Jan Poortmans P, Verhulst S, et al. Circulating ECV-associated miRNAs as potential clinical biomarkers in early stage HBV and HCV induced liver fibrosis. Front Pharmacol. 2017;8:56.

120. Liang G, Liu G, Kitamura K, et al. TGF-beta suppression of HBV RNA through AID-dependent recruitment of an RNA exosome complex. PLoS Pathog. 2015; 11:e1004780.

121. Yang X, Li H, Sun H, et al. Hepatitis B virus-encoded microRNA controls viral replication. J Virol. 2017. https://doi.org/10. 1128/JVI.01919-16.

122. Chen Y, Shen A, Rider PJ, et al. A liver-specific microRNA binds to a highly conserved RNA sequence of hepatitis B virus and negatively regulates viral gene expression and replication. FASEB J. 2011;25:4511-21.

123. Brain O, Owens BM, Pichulik T, et al. The intracellular sensor NOD2 induces microRNA-29 expression in human dendritic cells to limit IL-23 release. Immunity. 2013;39:521-36.

124. Mao R, Nie H, Cai D, et al. Inhibition of hepatitis B virus replication by the host zinc finger antiviral protein. PLoS Pathog. 2013;9:e1003494.

125. Ma C, Xu W, Yang Q, et al. Osteopetrosis-associated transmembrane protein 1 recruits RNA exosome to restrict hepatitis B virus replication. J Virol. 2020. https://doi.org/10.1128/JVI. 01800-19.

126. Naito Y, Hamada-Tsutsumi S, Yamamoto Y, et al. Screening of microRNAs for a repressor of hepatitis B virus replication. Oncotarget. 2018;9:29857-68.

127. Shiromoto F, Aly HH, Kudo H, et al. IL-1beta/ATF3-mediated induction of Ski2 expression enhances hepatitis B virus $\mathrm{x}$ mRNA degradation. Biochem Biophys Res Commun. 2018;503:1854-60.

128. Dai X, Zhang W, Zhang H, et al. Modulation of HBV replication by microRNA-15b through targeting hepatocyte nuclear factor 1alpha. Nucleic Acids Res. 2014;42:6578-90.
129. Qiao L, Luo GG. Human apolipoprotein E promotes hepatitis B virus infection and production. PLoS Pathog. 2019;15:e1007874.

130. Khatua AK, Taylor HE, Hildreth JE, et al. Inhibition of LINE-1 and Alu retrotransposition by exosomes encapsidating APOBEC3G and APOBEC3F. Virology. 2010;400:68-75.

131. Ashraf Malik M, Ishtiyaq Ali Mirza J, Umar M, et al. CD81(+) exosomes play a pivotal role in the establishment of hepatitis $\mathrm{C}$ persistent infection and contribute toward the progression of hepatocellular carcinoma. Viral Immunol. 2019;32:453-62.

132. Fan CG, Wang CM, Tian C, et al. miR-122 inhibits viral replication and cell proliferation in hepatitis $\mathrm{B}$ virus-related hepatocellular carcinoma and targets NDRG3. Oncol Rep. 2011;26:1281-6.

133. Wilkins C, Woodward J, Lau DT, et al. IFITM1 is a tight junction protein that inhibits hepatitis $\mathrm{C}$ virus entry. Hepatology. 2013;57:461-9.

134. Ji XJ, Ma CJ, Wang JM, et al. HCV-infected hepatocytes drive CD4+ CD25+ Foxp3+ regulatory T-cell development through the Tim-3/Gal-9 pathway. Eur J Immunol. 2013;43:458-67.

135. Giugliano S, Kriss M, Golden-Mason L, et al. Hepatitis C virus infection induces autocrine interferon signaling by human liver endothelial cells and release of exosomes, which inhibits viral replication. Gastroenterology. 2015;148(392-402):e13.

136. Cheng JC, Tseng CP, Liao MH, et al. Activation of hepatic stellate cells by the ubiquitin C-terminal hydrolase 1 protein secreted from hepatitis C virus-infected hepatocytes. Sci Rep. 2017;7:4448.

137. Jin J, Tang S, Xia L, et al. MicroRNA-501 promotes HBV replication by targeting HBXIP. Biochem Biophys Res Commun. 2013;430:1228-33.

138. Zhang Z, Chen J, He Y, et al. miR-125b inhibits hepatitis B virus expression in vitro through targeting of the SCNN1A gene. Arch Virol. 2014;159:3335-43.

139. Shrivastava S, Devhare P, Sujijantarat N, et al. Knockdown of autophagy inhibits infectious hepatitis $\mathrm{C}$ virus release by the exosomal pathway. J Virol. 2015;90:1387-96.

Publisher's Note Springer Nature remains neutral with regard to jurisdictional claims in published maps and institutional affiliations. 